\title{
Reducing Attribute Non-Attendance Risk in Choice Experiment: An application of Design Attribute Relative Importance Index for Waste Management Service Provision in Segmented Markets
}

\author{
Shehu Usman Adam ${ }^{1}$, Shaufique F. Sidique ${ }^{2 *}$ and Mad Nasir Shamsudin ${ }^{3}$ \\ ${ }^{1}$ Institute of Agricultural and Food Policy Studies, Putra Infoport, Universiti Putra Malaysia, \\ 43400 UPM Serdang, Selangor Darul Ehsan, Malaysia \\ ${ }^{2}$ School of Business and Economics, Universiti Putra Malaysia, 43400 UPM Serdang, \\ Selangor Darul Ehsan, Malaysia \\ ${ }^{3}$ Faculty of Forestry and Environment, Universiti Putra Malaysia, 43400 UPM Serdang, \\ Selangor Darul Ehsan, Malaysia
}

\begin{abstract}
Attribute non-attendance is an estimation problem that biases welfare estimates in the economic valuation of environmental goods when choice experiment (CE) is used. The potential for observing the problem is increased when segmented markets with dissimilar preferences exist for environmental goods but not captured in the experimental design for $\mathrm{CE}$. The current procedure for avoiding this problem relies on qualitative techniques, which limits applications to large samples and thus prone to bias. To reduce such bias, this study used an alternative technique based on the design-attribute relative importance index (DARII) to determine respondents' prioritization of attributes within and across markets. Our results in solid waste management services demonstrate that all selected attributes were highly ranked across markets. While such finding conforms to expectations based on the interview, we found a statistically significant difference in attributes prioritization across markets. We thus conclude that assuming equal priority for attributes in different market segments may be improper but possibly tangled when the qualitative method is used. As such, the study recommends CE studies to use DARII before the experimental design stage.
\end{abstract}

Published: 31 December 2020

(Mad Nasir Shamsudin)

* Corresponding author

Keywords: Attribute non-attendance, choice experiment, DARII, design attributes, heterogeneous market 


\section{INTRODUCTION}

Following the first application of choice experiment (CE) to environmental valuation by Adamowicz et al. (1994), growing interest in its use evokes discussions related to methodological improvements. These discussions particularly emphasize pre-modeling issues prior to the experimental design stage (Bliemer \& Rose, 2009; Coast \& Horrocks, 2007; Kløjgaard et al., 2012; Louviere et al., 2011; Rose \& Bliemer, 2009). Attribute non-attendance constitutes one of the recent, experimental design-related concerns in $\mathrm{CE}$ (Alemu et al., 2013; Hess, 2014, 2012). This problem, which biases welfare estimates, is attributable to the relevant ${ }^{1}$ design-attributes selection that constitutes the first step in $\mathrm{CE}$ (Alemu et al., 2013; Coast and Horrocks, 2007; Hanley et al., 1998; Hensher et al., 2005).

More importantly, the validity of CE studies depends on a researcher's competence to correctly specify a limited number of design attributes about which the target population holds high preferences (Hess \& Hensher, 2010; Mangham et al., 2008). Another related constraint that warrants attribute prioritization prior to experimental design in $\mathrm{CE}$ is the model parsimony requirement at the post-design or modeling stage, which does not allow the inclusion of all attributes for the valuation of an environmental resource. Therefore, recent studies have consistently used fewer design attributes (De Bekker-Grob et al., 2012), necessitating prioritization of the attributes' subset for experimental design at the pre-design stage despite the enormous number of attributes possessed by environmental resources.

Surprisingly, despite attribute selection for CE experimental design in economic valuation not being strictly based on economic theory, CE studies explaining how this subset of design-attributes are determined are sparse (Kløjgaard et al., 2012; Mangham et al., 2008). The CE technique is based on Lancaster's theory of value, where utility is conceptualized to depend on the attributes possessed by goods or services (Lancaster, 1966). However, it is implausible to completely describe things via their attributes (Bateman et al., 2002). After selecting the most choice-influencing subset of attributes, the rest are assumed to be captured by the error term specified as a stochastic component in the random utility framework. If the most choice-influencing attributes with the highest preference across respondents are not included, the omission of such important predictors will bias estimated parameters and thus, welfare measures. This could lead to inefficient allocation of resources arising from underestimation or overestimation of welfare values, leading to poor or inappropriate environmental and resource related policies.

It is recently noted that attribute non-attendance arises because some respondents have low preferences for certain attributes among the bundle of alternative choices (Alemu et al., 2013; Hess \& Hensher, 2010). This arises as a result of including low preference attributes in the experimental design of a CE. How can the most important subset of

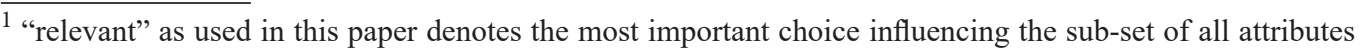
about which respondents hold the highest preferences in relative terms.
} 
attributes be determined at the design stage to avoid the inclusion of attributes with low preference based on the current qualitative procedure? This method entails interviewing a sample of stakeholders (Coast and Horrocks, 2007; Hanley et al., 1998; Mangham et al., 2008; Kløjgaard et al., 2012). The problem with interviewing these stakeholders, as it is currently done, arises because the perception of "relative importance" is subjective and allows preferences for attributes to be reached only in small samples. Adam et al. (2013) attempted to address this issue by using an indicator called DARII to determine relative importance in larger samples for a homogeneous market. However, the assumption of a homogenous market, although maintained in most CE studies, is quite inaccurate.

This inaccuracy emerges because the markets for virtually all products are, in reality, imperfect. They contain some homogenous market segments within the bigger markets that are most often heterogeneous (Dibb \& Simkin, 2009; Smith, 1956; Wind, 1978;). The markets for environmental resources are prototypes of such heterogeneous markets. This holds for solid waste management service markets where attributes exert unequal relevance across heterogeneous market segments (Naz \& Naz, 2005). It also conforms to the expectations of market segmentation advocates (Jones et al., 2005).

Since most solid waste municipalities have different market segments, applying the same attributes would be inappropriate (Adepitan, 2010; Coffey \& Coad, 2010). This study aims to address this issue by demonstrating an application of DARII within and across market segments prior to the experimental design stage in CE. This is important to avoid biased estimates that could be induced by attribute non-attendance resulting from imposing the same experimental design on respondents across different markets where preference structure may be dissimilar. We conducted a survey in Lagos, Nigeria on its solid waste management service market, which was characterized by two major segments: affluent and poor neighborhoods. These segments are apparently different in some service attributes (Adepitan, 2010). Lagos State is Nigeria's most populous state, featuring both affluent and poor communities with a population running between 14 million to 21 million people (Leithead, 2017). It has the highest population density in Nigeria and it was chosen because of its remarkably impressive reforms. Once tagged the dirtiest city in the world but now has the most organized solid waste management system in Nigeria with over 300 private sector companies operating in its solid waste management service sector (Adam et al., 2015; Olukanni \& Nwafor, 2019).

\section{METHODS}

Relative importance index (RII) is usually assessed in cases where variables are perceived important, but perceptions on subjective relative importance varies across respondents. To do that, studies have relied on an average ranking of importance to determine the overall importance rating of each variable. This assessment is common in the literature on project 
risk management within the field of construction engineering. Usually the assessment begins with variables ${ }^{2}$ identification through a literature review (Andi, 2006; El-Sayegh, 2008; Huwang et al., 2013; Kangari, 1995). The variables are then verified through interviews and expert discussions (Aziz, 2013; Bari et al., 2012; Ramanathan et al., 2012). This entire procedure is consistent with the processes involved in identifying design attributes in $\mathrm{CE}$ literature.

Since the first application of this method to attribute selection procedure by Adam et al. (2013), more recent studies have applied it in CE predesign attribute selection. These include an application in solid waste management by Basiru et al. (2017). Other applications were also demonstrated both in transport choice preferences pre-design and job choice determination by Kaffashi et al. (2016) and Alagabi et al. (2017), respectively.

The magnitudes of RII for different attributes are rated either based on perceived mean value and standard deviation or the percentage of respondents assigning a high rating to a factor. Studies relying on mean value and standard deviation as a basis for establishing attributes' relative importance compute the magnitude using the following equation:

$$
\text { Relative Importance Index, } R I I_{\forall A_{i}}=\frac{\sum W_{y i} X_{i}}{n_{i}}, \quad\left(0 \leq R I I_{\forall A_{i}} \geq 1\right)
$$

$$
\text { for } A_{i}=\left(A_{1}, A_{2}, A_{3}, \ldots, A_{n}\right)
$$

where $A_{i}$ denotes the number of attributes ranging from $A_{1}$ to $A_{n} . W y_{i}$ denotes the $\mathrm{y}^{\text {th }}$ weight assigned to responses on the importance of $i^{\text {th }}$ attribute as perceived by respondents, Meanwhile, $y=1,2,3, \ldots Y$, where $\mathrm{Y}$ is the highest weight $\mathrm{W}_{\mathrm{i}}$ can assume. $X_{i}$ is the frequency of the weight $\mathrm{W}_{\mathrm{y}}$ assigned for an $i^{\text {th }}$ attribute. $n_{i}$ denotes the total number of responses to an $i^{\text {th }}$ attribute in a sample which may not necessarily be the same for all attributes due to issues such as non-response. Note that the $Y$ for any given $W_{i}$ is the highest value of the response anchor used while its size depends on the rating scale employed. Generally, authors use response anchors with a five-point or seven-point Likert-type rating scale. In both cases, 1 denotes least effect or influence while 5 or 7 denotes the highest effect.

However, in recent applications, some modifications of RII that incorporate some weighting factors to the denominator in equation (1) are adopted (see Ramanathan et al., 2012 for a review). Authors using these versions noted that mean values and standard deviations of individual attributes are not statistically suitable for computing relative importance. This is because values obtained based on equation (1) would not reflect any relative relationships among attributes of interest to rationalise comparisons (Aziz, 2013; Bari et al., 2012). Thus, this group of authors suggest the use of RII variants that generate values that are easily comparable in relative terms. One of such versions is computed as follows:

${ }^{2}$ Here, the factors or variables referred to in the context of engineering literature is adopted to denote attributes in CE (see Adam et al., 2013) 
Relative Importance Index, $R I I_{\forall A_{i}}=\frac{\sum W_{y i} X_{i}}{n_{i} * Y}, \quad\left(0 \leq R I I_{\forall A_{i}} \geq 1\right)$

where the magnitude of the computed RII in equation (1) is weighted by the highest value $(Y)$ of the response category based on the adopted rating scale. Therefore, the rating index is expected to range between 0 and 1 regardless of the rating scale used. The closer an attribute's rating index is to 1, the higher is its perceived importance relative to others and vice versa. Therefore, the adjusted RII originally obtained through a Likert scale is transformed into a continuum ranging from 0 to 1 (Adam et al., 2013).

\section{Applicability of RII in Examining Group-Difference in DARII}

The procedure and objective involved in the RII coincide with those of design-attribute selection in CE studies. This study's assessment of group-difference in DARII employed the adjusted RII on account of its preference over an unweighted RII (Adam et al., 2013). The application of RII in engineering literature acknowledges the possibility of observing differences in attributes' RII across a distinct group of subjects (respondents), particularly when there are apparent differences across groups. These differences, for example, are distinguishable through demographic characteristics. Such an assessment is deemed important because a composite value of RII reflecting an arbitrary combination of subgroups may not reflect the specificities of individual groups. Accordingly, a few studies examined these differences. This includes comparing perceived risk factors between two groups (El-Sayegh, 2008) or more (Chan \& Kumaraswamy, 1997). Therefore, based on the RII in (2), in cases where heterogeneous groups (markets) are apparent, DARII may be computed as:

$$
\begin{aligned}
& C D A R I I_{\forall A_{i}}=\frac{\sum W_{c i} X_{c i}}{n_{c i} * Y}, \quad(0 \leq \mathrm{CDARII} \geq 1), \forall A_{i s} \\
& D \ddot{A R I} I_{\forall A_{i}}=\frac{\sum W_{c i} X_{a i}}{n_{1 i} * Y}, \quad(0 \leq D \ddot{A R I I} \geq 1), \forall A_{i s} \\
& D \dddot{A R} I I_{\forall A_{i}}=\frac{\sum W_{c i} X_{b i}}{n_{2 i} * Y}, \quad(0 \leq D \dddot{A R} I I \geq 1), \forall A_{i s}
\end{aligned}
$$

where $n_{i}, A, W, X$ and $Y$ are as defined in equation (1) but here, $n_{1}, n_{2} \ldots, n_{n} \in n_{i}$ while DÄRII $_{\forall A_{i}} \not \equiv$ DÄRII $\forall A_{i}$ and both are distinct from $C_{D A R I I} \forall A_{i}$. The first two represent

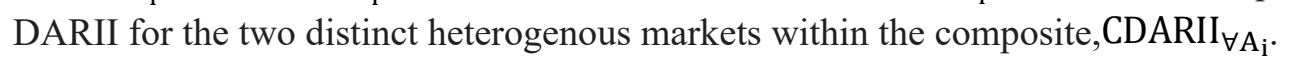

In $\mathrm{CE}$ applications, the combination of the characteristics theory of value (Lancaster, 1966) and the theory of random utility (McFadden, 1973, in Hanley et al., 2001) paves the way for estimating observed respondents' preferences (choices) among different bundles of environmental resources (goods). This is demonstrated in equation (6). 


$$
U_{i j}=V\left(A_{i j}\left(Z_{i}\right)\right)+\varepsilon\left(A_{i j}\left(Z_{i}\right)\right)
$$

where each respondent's indirect utility function $\left(U_{i}\right)$ depends on preferences made from some choice set $S$, over a finite number of alternative environmental goods $(j)$. Besides, $\left(U_{i}\right)$ is disaggregated into two components, deterministic $(V)$ and stochastic $(\varepsilon)$. The utility attainable from various alternatives $(j)$, is expected to depend on the set of attributes $\left(A_{i}\right)$ of the alternatives. In addition, it is understood that such attributes are viewed differently by different individuals based on the variations in their socioeconomic characteristics denoted by (Z) (Hanley et al., 1998). To obtain welfare estimates, cost or price attributes are usually expected to form part of the bundle constituting each alternative $(j)$.

Just like the case with DARII, researchers are often interested in estimating differences in welfare across sub-groups (Birol et al., 2009; Naz \& Naz, 2005). In similar cases, equation (6) could be taken as the composite model. However, a case involving two subgroups will be more accurately represented by equations (7) and (8).

$$
\begin{aligned}
& U_{a i j}=V\left(A_{i j}\left(G_{i}\right)\right)+\varepsilon\left(A_{i j}\left(G_{i}\right)\right) \\
& U_{b i j}=V\left(A_{i j}\left(Q_{i}\right)\right)+\varepsilon\left(A_{i j}\left(Q_{i}\right)\right)
\end{aligned}
$$

where $A_{i j}$ is the vector of attributes in different scenarios and $G_{j}$ the vector of respondents' characteristics. Note that in this case, despite $G_{i}$ and $Q_{i}$ are $\in$ of $Z_{i}$ in (6), it is common to observe results yielding values such that $U_{a i j} \neq U_{b i j} \neq U_{i j}$ (Birol et al., 2009). This implies that average preferences for $A_{i j}$ differs across sub-groups. Therefore, if the difference that defines sub-groups into distinct units is related to between-groups, divergence in average demographic characteristics, a separate experimental design may be required depending on DARII's result.

An application of choice set based on the same experimental design to sub-groups could bias estimates. This is because the set of attributes with the highest preferences withingroups might not be the same as the most preferred subset across groups. Furthermore, attribute subsets most preferred within and across groups may not be the same as the most preferred composite subset obtainable by pooling the sub-groups. This is evident in RII studies (Chan \& Kumaraswamy, 1997; El-Sayegh, 2008).

\section{Application of DARII to Solid Waste Management Improvement}

This study began with the identification of relevant design-attributes through a literature survey, discussion with experts, and regulatory officials. In addition, a few households from the target population were interviewed. Attribute compilation from the literature was 
limited to past valuation studies on solid waste management improvement. The different sources yielded twenty-three (23) attributes, including five attributes specific to solid waste management service provision in Lagos. These included enforcement on defaulting tenements, waste containerisation, pre-collection services, waste evacuation from canals, and door-to-door collection services.

However, three attributes were deemed irrelevant based on interview feedback from stakeholders. The irrelevant attributes included water pollution and psychological fears initially obtained from Pek and Jamal (2011), as well as changes in the mix of collection trucks adopted from Afroz et al. (2009), and Afroz and Masud (2011). Following the procedure outlined in Coast and Horrocks (2007) and Hanley et al. (1998), the attributes deemed irrelevant were finally deleted, leaving twenty attributes. The remaining attributes were synthesised into four broad groups for organisation purposes. The breakdown structure is as shown in Table 1.

Table 1

Solid waste management services design-attributes breakdown structure

\begin{tabular}{|c|c|c|}
\hline $\mathbf{S} / \mathrm{N}$ & $\begin{array}{c}\text { Solid waste Management Service } \\
\text { Attributes }\end{array}$ & Sources \\
\hline 1. & Waste Charges & $\begin{array}{l}\text { Jin et al. (2006), Othman (2007), Karousakis and Birol } \\
\text { (2008), Pek and Jamal (2011) }\end{array}$ \\
\hline 2. & Schedule and Frequency of collection & $\begin{array}{l}\text { Das, et al. (2010), Othman (2007), Afroz, and Masud } \\
\text { (2011), Othman (2007), Jin et al. (2006) }\end{array}$ \\
\hline 3. & Bill Discount & Basili, et al. (2006), Caplan, et al. (2007), Adam et al. (2015) \\
\hline 4. & Free Container & $\begin{array}{l}\text { Adam et al. (2015), Afroz and Masud (2011), Jin et al. } \\
\text { (2006) }\end{array}$ \\
\hline 5. & $\begin{array}{l}\text { Door-to-Door Collection and Pre- } \\
\text { Collection }\end{array}$ & Adam et al. (2015), Afroz and Masud (2011) \\
\hline 6. & Waste Categories & Adam et al. (2015) \\
\hline 7. & Waste Separation and Waste storage & Afroz and Masud (2011), Jin et al. (2006), Othman (2007) \\
\hline 8. & Water pollution & Pek and Jamal (2011) \\
\hline 9. & Disposal Method & Afroz and Masud (2011) \\
\hline 10. & Waste Transport & Othman (2007), Afroz and Masud (2011) \\
\hline 11. & Collection Trucks Mix & Afroz and Masud (2011) \\
\hline 12. & Psychological Fear & Pek and Jamal (2011) \\
\hline 13. & Changes in Franchisee & Adam et al. (2015) \\
\hline 14. & Defaulters Enforcement & Adam et al. (2015) \\
\hline 15. & Land Use & Pek and Jamal (2011) \\
\hline 16. & Services Provider (Private/Public) & $\begin{array}{l}\text { Jin et al. (2006), Afroz and Masud (2011), Adam et al. } \\
\text { (2015) }\end{array}$ \\
\hline 17. & Air pollution & Pek and Jamal (2011) \\
\hline 18. & Noise pollution & Jin et al. (2006) \\
\hline 19. & Canal Evacuation & Adam et al. (2015) \\
\hline
\end{tabular}

Source: Authors' solid waste management service attributes compilation from literature 


\section{Design-Attributes in Questionnaire}

Both the monetary and non-monetary design-attributes were included in the questionnaire (Table 1). This pre-design analysis caters to our upcoming CE study that will estimate the monetary compensation households are willing to accept to source-separate the solid waste they generate. Therefore, a bill discount is considered as a policy-relevant monetary design-attribute. Our choice of this monetary attribute was motivated by interview feedback from regulatory officials. A top executive member of the Lagos state waste management authority (LAWMA) noted that LAWMA proposes to subsidise the effort of households to segregate their solid waste into designated recyclable categories. LAWMA will collect the separated recyclables, while the source-separator will be given a discount of $50 \%$ on the monthly bill (Adam et al., 2015). Due to this policy consideration, other potential monetary design-attributes in Table 1 were deemed policy-irrelevant, reducing the list from 23 to 17 attributes, including other non-monetary attributes.

One of the motivations of this study is to examine the possible differences in DARII for attributes across two solid waste management service market segments. Intuitively, we expected pre-collection service and door-to-door collection to have different demand structures across the market segments. In Lagos, pre-collection service involves the collection of waste from households using lightweight vehicles (motorized tricycles). These vehicles have the advantage of accessing roads in urban slum areas which are usually narrow with no bituminous treatments, making it inaccessible to heavy compactor trucks. These wastes will then be transferred to compactor trucks for final transportation to landfills. Meanwhile, the most common mode of waste collection in affluent areas is door-to-door collection using heavy trucks.

\section{Questionnaire Structure and Measure}

The questionnaire used in this study is divided into two sections. The first section elicits demographic information of the respondents, while the second section presents a list of solid waste management service improvement attributes. Respondents were asked to rate each of the attributes to determine the most important subset using a Likert-type rating scale for scoring their perceived importance for each attribute. The response anchors for the rating scale are properly worded to ensure reliable responses. To guarantee that, a prior interview was conducted whereby respondents were asked to explain service attributes that "affect" their satisfaction. In expressing their opinions, they frequently expressed the degree to which attributes' inclusion affected their utility using the words: 'importance', 'effect', and 'impact'.

Based on that, we chose to use a response anchor we defined as, "degree of impact' on respondents' satisfaction with the inclusion of an attribute in improved service provision. This conforms to the anchor used in engineering literature. Kartam and Kartam (2001) and El-Sayegh (2008) used 'degree of impact', while Kangari (1995) and Hwang et al. 
(2013) used 'degree of importance'. Meanwhile, Chan and Kumaraswamy (1997), and Aziz (2013) used 'degree of effect'. These response anchors are usually applied to fivepoint or seven-point Likert scales. Kartam and Kartam (2001), Kangari (1995), Hwang et al. (2013), Chan and Kumaraswamy (1997), Aziz (2013), and El-Sayegh (2008) all used a five-point Likert scale, but Kometa et al. (1994) used a seven-point Likert scale. Accordingly, this study employs a five-point Likert scale where the lowest response anchor (1) denotes "low impact on satisfaction", while the highest response anchor (5) denotes "high impact on satisfaction".

\section{Sampling and Questionnaire Administration}

The provision of solid waste management services slightly differs across affluent and poor neighborhoods (Adepitan, 2010). This discrepancy is not a direct consequence of government policy, but was due to inadequate infrastructure in urban slum areas, specifically accessible roads (Adam et al., 2015). Therefore, the population can be stratified into affluent neighborhoods with accessible roads, and urban slum areas with often inaccessible roads.

Due to the apparent difference in service provision across affluent and poor urban areas, a stratified cluster sampling method was considered appropriate. This was due to the absence of a sample frame arising from non-availability of information. One community was randomly selected from each stratum. Finally, 100 questionnaires were administered in each stratum, yielding a total of 200 observations. The Surulere local government area represented the affluent stratum while the Apapa-Iganmu community development area constituted the selected poor neighborhood stratum. Data was collected through face-to-face questionnaire interviews of household representatives in the selected areas from September to November, 2012. The interviews were conducted by ten trained enumerators. A total of 200 interviews were finally conducted with 100 respondents in each stratum.

\section{RESULT AND DISCUSSION}

\section{Socioeconomic Characteristics of Households}

A response rate of up to $80 \%$ was achieved during data collection. We expected this since the questionnaire was kept very brief (occupying only one page) and was administered via face-to-face interviews. Interviewers were also specifically instructed to remind respondents to revisit missing answers and this yielded up to $99 \%$ usable questionnaire responses where only two questionnaires from the affluent stratum were excluded from analysis on account of incomplete responses. The number of respondents included in our final sample was 198. Table 2 shows a summary of the surveyed sample characteristics.

Male and female respondents constituted $55 \%$ and $45 \%$ of the sample, respectively. This approximates the state's gender distribution (based on the 2006 Census) where males and females account for $51.8 \%$ and $48.2 \%$ of the population. The average age of the sample 
was 35.6 years, with the youngest being 18 and the oldest being 61 . Respondents were grouped according to reported ages into three cohorts of 18-24, 25-40 and above 40 . These cohorts were respectively labeled young adult, middle-aged adult and older adults. The majority of these respondents are middle-aged adults $(67.2 \%)$, followed by older adults $(24.7 \%)$, and young adults $(8.1 \%)$. About $80 \%$ of respondents were married while the rest were either single or divorced. The highest percentage of households $(73.7 \%)$ had a formal education ranging from primary $(10.1 \%)$, secondary $(22.2 \%)$ to tertiary $(41.4 \%)$. While the remaining $26.3 \%$ had no formal education. This literacy rate is slightly higher than the national average of $71.6 \%$. This is expected since a nation-wide literacy survey report showed that the literacy rate was higher in Lagos than in other Nigerian states (NBS, 2010). Most households worked in the private sector (55.1\%), followed by the public sector $(23.7 \%)$ and the remaining $21.2 \%$ were either pensioners or unemployed. Households

Table 2

Summary statistics on households' socio-economic characteristics

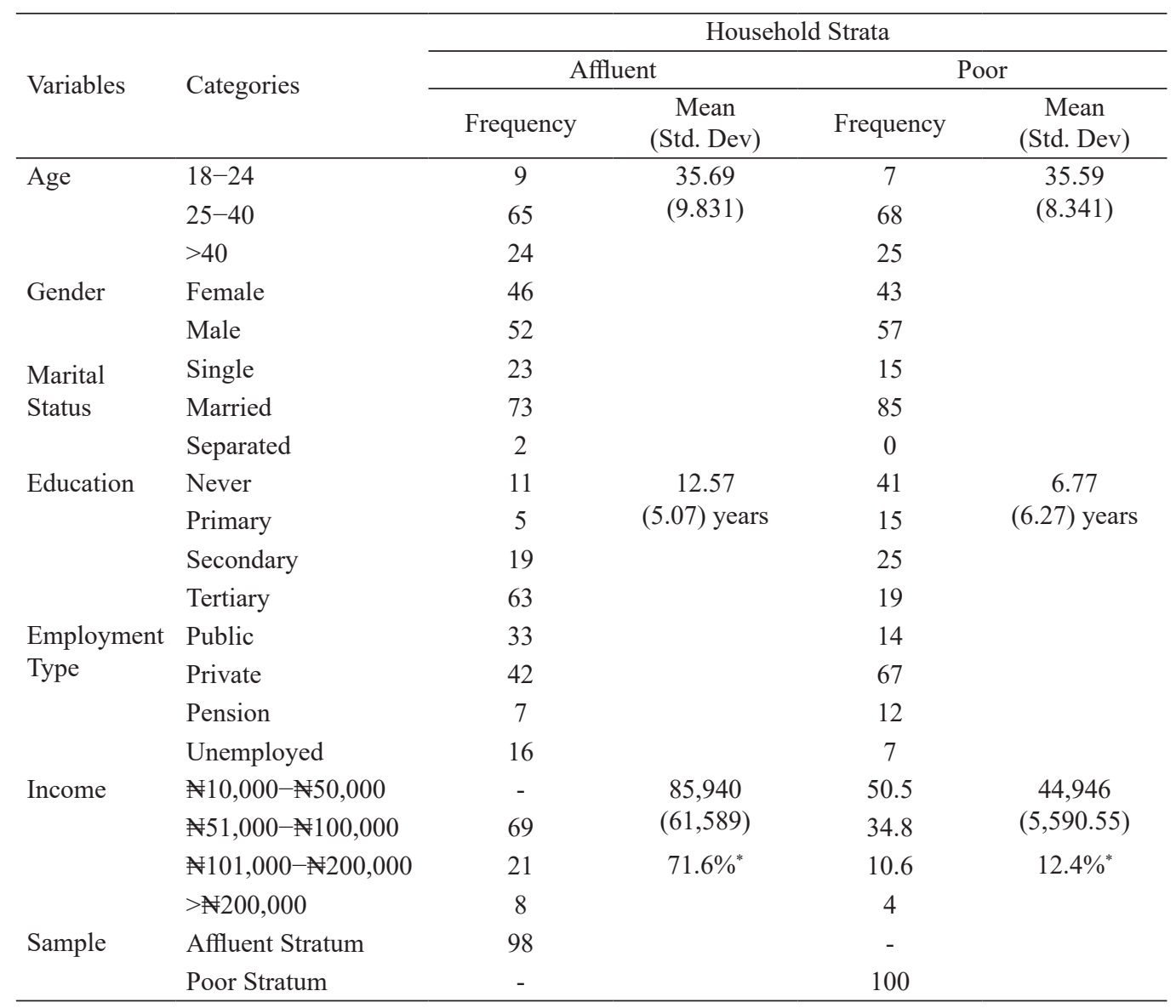

${ }^{*}$ Denotes percentage of relative standard deviations. 
within the low income stratum earn between $\$ 10,000-\$ 50,000$ monthly while the majority of households in the affluent stratum earned income ranging from $\$ 1,000-100,000$. However, it is worth noting that at the time of the study's field survey in 2012 USD/Naira exchange rate hovered around US\$1 to 160 against US\$ 1 to 387 in the third quarter of 2020 .

\section{Composite DARII Computation for both Communities}

The composite DARII values were calculated using equation (3). The result shown in Table 3 conforms to prior expectations given our previous interview results that showed that all attributes finally included in this survey are important. This is evidenced by DARII $>0.5$ for all attributes considered. However, to maintain model parsimony, not all of these important attributes can be included in a CE model. Previous CE studies did not report how this problem can be resolved quantitatively at the pre-design stage. The few studies that attempted to address this problem use a qualitative procedure, which allows surveying only limited opinions via interviews (Coast \& Horrocks, 2007; Kløjgaard et al., 2012). Applying a composite DARII technique employed in this study offers an alternative quantitative approach that allows surveying wider opinions with limited subjectivity, since it is not constrained by coding and developing themes peculiar to its qualitative counterpart.

Table 3

Design-attributes relative importance index for both communities with dimensions

\begin{tabular}{|c|c|c|c|c|c|c|c|}
\hline $\begin{array}{c}\text { Category } \\
\text { Name }\end{array}$ & $\begin{array}{l}\text { Attribute } \\
\text { ID }\end{array}$ & Attribute Label & $\leq 2$ & 3 & $\geq 4$ & DARII & Ranking \\
\hline \multirow{7}{*}{$\begin{array}{l}\text { Pollution- } \\
\text { Related } \\
\text { Attributes }\end{array}$} & 1 & Source-separation & 11.1 & 18.7 & 70.2 & 0.78 & 4 \\
\hline & 2 & Disposal Method & 12.6 & 39.9 & 47 & $0.67 *$ & 10 \\
\hline & 3 & Storage Material & 10.1 & 22.2 & 67.7 & $0.75^{*}$ & 6 \\
\hline & 4 & Transport Method & 32.3 & 36.9 & 30.8 & 0.58 & 14 \\
\hline & 5 & Canal Evacuation & 22.7 & 24.7 & 52.5 & 0.65 & 12 \\
\hline & 6 & Air Pollution & 41.4 & 23.7 & 34.8 & $0.57^{*}$ & 15 \\
\hline & 7 & Noise Pollution & 48 & 28.3 & 23.7 & 0.51 & 17 \\
\hline \multirow{5}{*}{$\begin{array}{l}\text { Regulatory } \\
\text { Issues }\end{array}$} & 8 & Separation Categories & 28.8 & 28.8 & 42.4 & 0.62 & 13 \\
\hline & 9 & Designated Collector & 40.9 & 25.8 & 33.3 & $0.57 *$ & 16 \\
\hline & 10 & Non-Payment Penalty & 6.1 & 15.7 & 78.3 & 0.79 & 3 \\
\hline & 11 & Land Use & 23.2 & 30.3 & 46.5 & $0.67 *$ & 11 \\
\hline & 12 & Franchisee Rotation & 10.6 & 36.4 & 53 & $0.70 *$ & 9 \\
\hline Service & 13 & Door-to-Door Collection & 19.7 & 11.1 & 69.2 & $0.75^{*}$ & 5 \\
\hline \multirow[t]{3}{*}{ Quality } & 14 & Pre-Collection & 17.7 & 20.7 & 61.6 & $0.70^{*}$ & 8 \\
\hline & 15 & Frequency & 6.6 & 16.2 & 77.3 & 0.81 & 2 \\
\hline & 16 & Schedule & 17.7 & 23.7 & 58.6 & 0.71 & 7 \\
\hline Monetary & 17 & Bill Discount & 2 & 15.7 & 82.3 & 0.82 & 1 \\
\hline
\end{tabular}

*Attributes with equal magnitudes of DARII are ranked according to the percentage of respondents scoring 4 or more. 
Attribute ranking shows that a waste bill discount in compensation for household effort and cost for separating waste into designated categories is the most important attribute (Table 3). Generally, this implies that households will be encouraged to vote for improvements in solid waste management services with source-separation if they know they can get a discount on their monthly bill. In terms of importance, this attribute is followed by frequency of waste collection, and a non-payment penalty, which denotes enforcement on defaulting tenements and adoption of source-separation. The ranking continues until the least important, which for the current sample are concerns regarding noise pollution during waste collection.

Table 4 shows the ten most important design-attributes for solid waste management improvement in Lagos. This does not suggest that all ten attributes could be included in a subsequent experimental design in any subsequent CE study. Rather, to achieve model parsimony and reducing CE task complexity, most studies include a maximum of about 4 to 6 attributes (Bekker-Grob et al., 2012; Marshall et al., 2010 in Johnson et al., 2013). This could be achieved with minimal subjectivity on the researcher's part using DARII. However, as important as these findings are, a composite DARII might not make much sense when applied to heterogeneous groups. This is because the magnitude of DARII may not reflect the degree of attributes' preferences within groups. One feasible way to disentangle this is through the exploration of possible differences in households' perceived relevance of attributes across sub-samples. This approach is suitable when an affected population is clustered or stratified by some characteristics. This is the main weakness of the composite DARII, so long as it is true that $\mathrm{DÄRII}_{\forall A_{i}} \not \equiv \mathrm{DÄRII}_{\forall \mathrm{A}_{i}}$ and both are distinct from $\mathrm{CDARII}_{\forall \mathrm{A}_{\mathrm{i}}}$. Therefore, a realistic alternative under that scenario is to separately compute $D \ddot{A R} R I_{\forall A_{i}}$ and $D \ddot{A} \ddot{R} I I_{\forall A_{i}}$ as shown in equations (4) and (5).

Table 4

Design-attributes relative importance index for both communities

\begin{tabular}{lccccc}
\hline Design-Attribute Label & $\mathbf{\leq 2}$ & $\mathbf{3}$ & $\mathbf{2 4}$ & DARII & Ranking \\
\hline Waste Bill Discount & 2 & 15.7 & 82.3 & 0.82 & 1 \\
Frequency & 6.6 & 16.2 & 77.3 & 0.81 & 2 \\
Non-Payment Penalty & 6.1 & 15.7 & 78.3 & 0.79 & 3 \\
Source-separation & 11.1 & 18.7 & 70.2 & 0.78 & 4 \\
Door-to-Door Collection & 19.7 & 11.1 & 69.2 & $0.75^{*}$ & 5 \\
Storage Material & 10.1 & 22.2 & 67.7 & $0.75^{*}$ & 6 \\
Schedule & 17.7 & 23.7 & 58.6 & 0.71 & 7 \\
Pre-Collection & 17.7 & 20.7 & 61.6 & $0.70^{*}$ & 8 \\
Franchisee Rotation & 10.6 & 36.4 & 53 & $0.70^{*}$ & 9 \\
Disposal Method & 12.6 & 39.9 & 47 & $0.67 *$ & 10 \\
\hline
\end{tabular}

*Attributes with equal magnitudes of DARII are ranked according to the percentage of respondents scoring 4 or more. 
Since differentiated markets exist for low-income and high-income communities (Adepitan, 2010), we needed to examine whether pre-design ranking of attributes remain the same across sub-groups. For this case, we assumed that the same underlying choicedetermining attributes in $\mathrm{CE}$ for both strata would be too restrictive and that imposition could create a problem of attribute non-attendance. This is because although respondents face the same set of attributes, on average, preference varies across groups and leads to including design attributes that may be preferred only by a market segment. The composite DARII is only appropriate for homogeneous samples (Adam et al., 2013).

To justify this stance, we used the independent-samples t-test to inferentially test the potential for significant differences in the relative importance rating of design attributes across the two strata of affluent and poor respondents. The result obtained is shown in Table 5. The result confirms that the market segment within which respondents belong significantly influences their perceived relative importance of solid waste management service attributes. This is evident by the statistical significance of the mean-difference scores of attributes across both segments of the market. In addition, we used effect size based on 'Eta squared' to provide a glimpse of the magnitude of percentage variance in the perceived rating of the importance of attributes induced by the differences in the market segment designation of respondents.

Table 5

Effect of market segment designation on perceived importance of attributes

\begin{tabular}{lccc}
\hline \multirow{2}{*}{ Attributes } & \multicolumn{2}{c}{ t-test for Equality of Means } & \multirow{2}{*}{ Effect Size $\left(\% \mathrm{Eta}^{2}\right)$} \\
\cline { 2 - 3 } Source-separation & Mean Difference & t-Statistic & 2.6 \\
Disposal Method & 0.330 & $2.297^{* *}$ & 23.9 \\
Storage Material & 0.892 & $3.803^{* * *}$ & 6.3 \\
Transport Method & 0.399 & $3.607^{* * *}$ & 4.7 \\
Canal Evacuation & 0.521 & $3.115^{* * *}$ & 18.2 \\
Air Pollution & 1.068 & $6.568^{* * *}$ & 0 \\
Noise Pollution & 0.035 & 0.191 & 17.2 \\
Separation Categories & 0.987 & $6.321^{* * *}$ & 0.8 \\
Designated Collector & 0.208 & 1.230 & 2.6 \\
Non-Payment Penalty & 0.359 & $2.267^{* *}$ & 22.5 \\
Land Use & 0.806 & $7.474^{* * *}$ & 12.3 \\
Franchisee Rotation & 0.801 & $5.170^{* * *}$ & 12.5 \\
Door-to-Door Collection & 0.604 & $5.285^{* * *}$ & 12.1 \\
Pre-Collection & 0.894 & $5.206^{* * *}$ & 6.2 \\
Frequency & 0.582 & $3.603^{* * *}$ & 4.3 \\
Schedule & 0.374 & $2.974^{* * *}$ & 42.5 \\
Bill Discount & 1.515 & $12.04^{* * *}$ & 13.4 \\
\hline
\end{tabular}

${ }^{* * *}$ and ${ }^{* *}$ respectively denote statistical significance at $1 \%$ and $5 \%$ levels. 
The interpretation of $\mathrm{Eta}^{2}$ is based on the explanations provided by Cohen (1988), where a percentage variation above $14 \%$ is perceived to constitute a large effect of variation in perceived importance due to the difference in respondents' designation of market segment. Based on this indicator, service attributes that include disposal method, canal evacuation, noise pollution, non-payment penalty, and waste collection schedule were largely rated differently across market segments. This suggests a further examination of DARII for each of the market segments.

\section{Comparison of DARII across Poor and Affluent Communities}

CE studies such as Naz and Naz (2005) were cautious regarding the existence of submarkets for the same commodity. Yet a sizeable number of CE studies have attempted comparing agents' utility for certain commodities or contracts across different strata of respondents, assuming the same set of relevant design-attributes (Birol et al., 2009; Christiadi and Cushing, 2007). These studies did not consider that each stratum might, on average, hold different relative importance ratings for attributes. The difference in priorities for design attributes might result in scenarios where a portion of the sample is forced to make choices based on relatively less important attributes. One known consequence of omitting a relevant explanatory variable in a regression model is biased estimates of parameters (Studenmund, 2005). An earlier pre-design computation of DARII for sub-groups could help detect this. Tables 5 and 6 exemplify the case for the two major strata (poor and affluent neighborhoods) in Lagos state solid waste management services provision. Respondents were presented with the same questionnaire containing a similar ordering of attributes to avoid ordering effect.

Ranking of attributes based on DARII in Table 6 and Table 7 are similar, but not the same. The attributes most preferred by the two sub-groups (Tables 6 and 7) are also different from the ones obtained under composite DARII (Table 4). This indicates that $D \ddot{A R} I I_{\forall A_{i}} \not \equiv D \ddot{A} \ddot{R} I I_{\forall A_{i}} \not \equiv C D A R I I_{\forall A_{i}}$. Two important conclusions are implied by

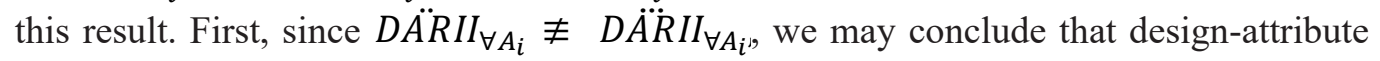
preferences in addition to the design-attribute subset deemed most preferred varies acrossgroups. Secondly, the design-attribute sub-set deemed most preferred within each sub-group is not the same as that obtained in the composite case. For instance, in an extreme case, there are findings that the evacuation of waste from canal and land use, which were all not in Table 4 (composite DARII), turned out to be among the top ten important attributes in different sub-groups (Tables 6 and 7). Furthermore, pre-collection and door-to-door collection services, which are both in Table 4, now seem to be mutually exclusive between Table 6 and Table 7, respectively. This conforms to our prior expectation because earlier interviews with stakeholders revealed that road accessibility is a problem in the urban slum 
Table 6

DARII in affluent communities

\begin{tabular}{clccccc}
\hline ID & Design-Attribute Label & $\mathbf{5}$ & $\mathbf{3}$ & $\mathbf{2}$ & DARII & Ranking \\
\hline 15 & Frequency & 8.2 & 9.2 & 82.7 & $0.84^{*}$ & 1 \\
13 & Door-to-Door Collection & 8.2 & 12.2 & 79.6 & $0.84^{*}$ & 2 \\
17 & Bill Discount & 4.1 & 27.6 & 68.4 & 0.76 & 3 \\
1 & Waste Segregation & 8.2 & 27.6 & 64.3 & $0.74^{*}$ & 4 \\
10 & Default Enforcement & 18.4 & 34.7 & 46.9 & $0.74^{*}$ & 5 \\
3 & Storage Material & 11.2 & 22.4 & 66.3 & 0.66 & 6 \\
16 & Schedule & 17.3 & 40.8 & 41.8 & 0.65 & 7 \\
12 & Franchisee Rotation & 16.3 & 49 & 34.7 & 0.63 & 8 \\
8 & Separation Categories & 26.5 & 42.9 & 30.6 & 0.59 & 9 \\
11 & Land Use & 28.6 & 46.9 & 24.5 & 0.58 & 10 \\
\hline
\end{tabular}

*Attributes with equal magnitudes of DARII are ranked according to the percentage of respondents scoring 4 or more.

Table 7

DARII in poor communities

\begin{tabular}{clccccc}
\hline ID & Design-Attribute Label & $\mathbf{3}$ & $\mathbf{3}$ & $\mathbf{2}$ & DARII & Ranking \\
\hline 17 & Bill Discount & 0 & 4 & 96 & 0.87 & 1 \\
14 & Pre-Collection & 1 & 3 & 96 & 0.85 & 2 \\
10 & Default Enforcement & 1 & 9 & 90 & $0.84^{*}$ & 3 \\
3 & Storage Material & 2 & 10 & 88 & $0.84^{*}$ & 4 \\
1 & Waste Segregation & 14 & 10 & 76 & 0.82 & 5 \\
5 & Canal Evacuation & 5 & 19 & 76 & 0.78 & 6 \\
16 & Schedule & 18 & 7 & 75 & $0.77^{*}$ & 7 \\
2 & Disposal Method & 3 & 25 & 72 & $0.77^{*}$ & 8 \\
15 & Frequency & 5 & 23 & 72 & $0.77^{*}$ & 9 \\
12 & Franchisee Rotation & 5 & 24 & 71 & 0.76 & 10 \\
\hline
\end{tabular}

* Attributes with equal magnitudes of DARII are ranked according to the percentage of respondents scoring 4 or more.

areas of Lagos. This finding supports assertions that no specific waste management strategy is ideal, even for regions within the same city (Coffey and Coad, 2010; Imam et al., 2008).

It is clear that attributes selection for experimental design based on a qualitative technique has attributable complications that will not permit access to large samples. Such complications include difficulties in coding and developing appropriate themes. While this could be managed by adopting a quantitative technique such as DARII, caution must be taken to understand the composition of the target population. Although we only require within group DARII for homogenous populations or markets, such computation might not be as obvious in a heterogeneous market. In these cases, both within-group and betweengroup DARII would be required for each market segment, as we demonstrated for the solid 
waste management service market in Lagos. If the same set of attributes were designed for all respondents in a heterogeneous market, the CE result might generate biased welfare estimates. This is because, as proven in this study, preferences for design-attributes vary across groups.

\section{CONCLUSION}

Our study was motivated by the quest for a less researcher-subjective approach that could be adopted to determine relevant design-attributes that allows access to a large sample at the pre-design stage of $\mathrm{CE}$, while at the same time limiting computational complications. This is aimed at reducing attribute non-attendance at the post-design stage of CE analysis in economic valuation. In order to achieve this, we adopted the relative importance (DARII) computation method. Explanations on the compatibility of DARII to the goals of CE were presented, including how it could be applied. We provided an example on households' predesign perceived relevance of solid waste management service provision for the case of a market with differentiated services characterised by two segments. The result was found to support a prior interview outcome on the importance of included attributes. This was evidenced by DARII values greater than 0.5 for all attributes.

Our findings also suggest that DARII had the advantage of providing information about the existence or non-existence of segmented markets for consideration in estimating economic value. This is important to explore, especially when the target population is stratified into sub-groups, where prices and other attributes of the service are usually not the same in sub-markets for similar but differentiated goods. Service provision was known to differ slightly across affluent neighborhoods and urban slum areas in prior interview responses (Adam et al., 2015). The key factor noted to be responsible for this was inadequate availability of accessible roads in urban-slum areas populated by the poor relative to the urban-affluent areas. We found that attributes desired in both markets were ranked differently based on varying values of DARII across groups. In addition, certain attributes were mutually exclusive, relevant only in one market, but not both. We further used the independent sample t-test to inferentially test the statistical significance of the difference in DARII value. The mean difference of the ratings was found to be statistically significant. This denotes the presence of segmented markets for solid waste management service provision in Lagos. Therefore, the DARII for each market differs from results assuming homogeneity from the pool response, which we dubbed the composite DARII.

Based on the above exposition on the importance of DARII, we suggest future studies to compute this index for all potential design-attributes obtained through a literature review and interviews. This will be required especially when design-attributes are large. In those cases, researchers' subjectivity would be reduced in prioritising what subset of important 
attributes to include in experimental design for CE. If attributes held most important from respondents' purview are selected, responses to CE choice tasks will be genuinely based on trade-offs rather than randomness. This will reduce the risk of observing attribute nonattendance, which has the undesirable effect of biasing welfare estimates. As evidenced in this study, researchers working on stratified or clustered target populations should compute DARII for each sub-group. If attributes ranking based on computed DARII are not the same across groups, especially when the difference between the ratings are statistically different across groups, then imposing the same design as done by some existing studies will be too restrictive.

\section{ACKNOWLEDGEMENT}

The authors thank Universiti Putra Malaysia for supporting the publication of this research through the Universiti Putra Malaysia GB-IPB Grant (Vote GP-IPB/ 2017/9542301).

\section{REFERENCES}

Adam, S. U., Shamsudin, M. N., Sidique, F. S., Abdul Rahim, K., \& Radam, A. (2013). Attribute prioritization in choice experiment pre-design: Suggested method and application to solid waste management service improvement. Journal of Energy Technologies and Policy, 3(11), 291-298.

Adam, S. U., Shamsudin, M. N., Sidique, S. F., Abdul, R. K., \& Radam, A. (2015). Determinants of privatized solid waste management service provision in Lagos. Journal of Environmental Planning and Management, 58(10), 1804-1826. doi:10.1080/09640568.2014.962126

Adamowicz, W., Louviere, J., \& Williams, M. (1994). Combining revealed and stated preference methods for valuing environmental amenities. Journal of Environmental Economics and Management, 26(3), 271292. doi:10.1006/jeem.1994.1017

Adepitan, A. (2010). Waste management in Nigeria; Lagos state model (1999-2009). Lagos, Nigeria: Jimsif Limited.

Afroz, R., \& Masud, M. M. (2011). Using a contingent valuation approach for improved solid waste management facility: Evidence from Kuala Lumpur, Malaysia . Waste Management, 31(4), 800-808. doi:10.1016/j. wasman.2010.10.028

Afroz, R., Hanaki, K., \& Hasegawa-Kurisu, K. (2009). Willingness to pay for waste management improvement in Dhaka city, Bangladesh. Journal of Environmental Management, 90(1), 492-503. doi:10.1016/j. jenvman.2007.12.012

Alagabi, A. A., Abdul-Majid, A., Rosemaliza, A. R. (2017). Attribute prioritization in discrete choice experiment: Challenges and suggested approach in a study on Malaysian Islamic Finance talent job choice. International Journal of Advances in Management and Economics, 6(5), 54-59.

Alemu, M. H., Mørkbak, M. R., Olsen, S. B., \& Jensen, C. L., (2013). Attending to the reasons for attribute non-attendance in choice experiments. Environmental Resource Economics 54(3), 333-359. doi:10.1007/ s10640-012-9597-8 
Andi. (2006). The importance and allocation of risks in Indonesian construction projects. Construction Management and Economics, 24(1), 69-80. doi:10.1080/01446190500310338

Aziz, R. F. (2013). Ranking of delay factors in construction projects after Egyptian revolution. Alexandria Engineering Journal 52(3), 387-406. doi:10.1016/j.aej.2013.03.002

Bari, N. A. A., Yusuff, R., Ismail, N., Jaapar, A., \& Ahmad, R. (2012). Factors influencing the construction cost of industrialised building system (IBS) projects. Procedia - Social and Behavioral Sciences 35, 689 - 696. doi:10.1016/j.sbspro.2012.02.138

Basili, M., Di Matteo, M., \& Ferrini, S. (2006). Analysing demand for environmental quality: A willingness to pay/accept study in the province of Siena (Italy). Waste Management, 26(3), 209-219. doi:10.1016/j. wasman.2004.12.027

Basiru, H. A., Yacob, M. R., Radam, A., and AbdManaf, F. (2017). Design-attributes relative importance index (DARII) analysis for improve solid waste collection services among households in Kano Metropolis, North-Western, Nigeria. IOSR Journal of Humanities and Social Science, 22(4), 104-111. doi:10.9790/0837-220405104111

Bateman, I. J., Carson, R. T., Day, B., Hanemann, M., Hanley, N., Hett, T., ... \& Swanson, J. (Eds.) (2002). Economic valuation with stated preference pechniques: A manual. Cheltenham, United Kingdom: Edward Elgar.

Birol, E., Das, S., \& Bhattacharya, N. R. (2009). Estimating the value of improved wastewater treatment: The case of River Ganga, India. Environmental Economy and Policy Research Discussion Paper Series, 43, 1-20. doi:10.1016/j.jenvman.2010.05.008

Blamey, R., Gordon, J., \& Chapman, R. (1999). Choice modelling: Assessing the environmental values of water supply options. Australian Journal of Agricultural and Resource Economics, 43(3), 337-357. doi:10.1111/1467-8489.00083

Caplan, A. J., Grijalva, T. C., \& Jakus, P. M. (2002). Waste not or want not? A contingent ranking analysis of curbside waste disposal options. Ecological Economics, 43(2-3), 185-197. doi:10.1016/s09218009(02)00210-0

Carlsson, F., \& Martinsson, P. (2008). Does it matter when a power outage occurs? - A choice experiment study on the willingness to pay to avoid power outages. Energy Economics, 30(3), 1232-1245. doi:10.1016/j. eneco.2007.04.001

Chan, D. W. M., \& Kumaraswamy, M. M. (1997). A comparative study of causes of time overruns in Hong Kong construction projects. International Journal of Project Management, 15(1), 55-63. doi:10.1016/ s0263-7863(96)00039-7

Christiadi, \& Cushing, B. (2007, March 29-31). Conditional logit, IIA, and alternatives for estimating models of interstate migration. In 46th Annual Meeting of the Southern Regional Science Association, (pp. 1-29). Charleston, South Carolina.

Christie, M., Hanley, N., Murphy, K., Wright, R., \& Hyde, T. (2006). Valuing the diversity of biodiversity. Ecological Economics, 58(2), 304-317. doi:10.1016/j.ecolecon.2005.07.034 
Coast, J., \& Horrocks, S. (2007). Developing attributes and levels for discrete choice experiments using qualitative methods. Journal of Health Services Research \& Policy 12(1), 25-30. doi:10.1258/135581907779497602

Coffey, M., \& Coad, A. (2010). Collection of municipal solid waste in developing countries. Malta, Europe: Gutenberg Press.

Das, S., Ekin, B., and Bhattacharya, N. R. (2010). Informing efficient solid waste management to improve local environmental quality and public health in West Bengal, India. In J. Bennett, \& E. Birol (Ed.), Choice experiments in developing countries; Implementation, challenges and policy implication (pp. 171-185). Massachusetts, USA: Edward Elgar.

De Bekker-Grob, E. W., Ryan, M., \& Gerard, K. (2012). Discrete choice experiments in health economics: A review of he literature. Health Economics, 21(2), 145-172. doi:10.1002/hec.1697

Dibb, S., \& Simkin, L. (2009). Bridging the segmentation theory/practice divide. Journal of Marketing Management, 25(3), 219-225. doi:10.1362/026725709X429728

El-Sayegh, S. M. (2008). Risk assessment and allocation in the UAE construction industry. International Journal of Project Management 26(4), 431-438. doi:10.1016/j.ijproman.2007.07.004

Hanley, N., Wright, R. E., \& Adamowicz, V. (1998). Using choice experiments to value the environment. Environmental and Resource Economics 11(3-4), 413-428.

Hensher, D. A., Rose, J. M., \& Greene, W. H. (2005). Applied choice analysis: A primer. Cambridge, England: Cambridge University Press.

Hess, S. (2012, January 22-26) Impact of unimportant attribute in stated choice surveys. In Transportation Research board $9^{1 s t}$ Annual Meeting (pp. 1-13). Washington, USA.

Hess, S. (2014) Impact of unimportant attributes in stated choice surveys. European Journal of Transport and Infrastructure Research, 14(4), 349 - 361. doi:10.18757/ejtir.2014.14.4.3041

Hess, S., \& Hensher, D. A. (2010). Using conditioning on observed choices to retrieve individual-specific attribute processing strategies. Transportation Research Part B: Methodological, 44(6), 781-790. doi:10.1016/j.trb.2009.12.001

Hwang, B.-G., Zhao, X., \& Gay, M. J. (2013). Public private partnership projects in Singapore: Factors, critical risks and preferred risk allocation from the perspective of contractors. International Journal of Project Management, 31(3), 424-433. doi:10.1016/j.ijproman.2012.08.003

Imam, A., Mohammed, B., Wilson, D., \& Cheeseman, C. (2008). Country Report: Solid waste management in Abuja, Nigeria. Waste Management , 28(2), 468-472. doi:10.1016/j.wasman.2007.01.006

Jin J., Wang Z., \& Ran S. (2006). Solid waste management in Macao: Practices and challenges

Waste Management, 26(9), 1045-1051. doi:10.1016/j.wasman.2005.08.006

Johnson, F. R., Lancsar, E., Marshall, D., Kilambi, V., Muhlbacher, A., Regier, D. A., ... \& Bridges, J. F. P. (2013). Constructing experimental designs for discrete-choice experiments: Report of the ISPOR conjoint analysis experimental design good research practices task force. Value in Health, 16(1), 3-13. doi:10.1016/j.jval.2012.08.2223 
Jones, S., Rees, L., Hall, D., \& Tang, A. (2005, December 5-7). Using market segmentation theory to select target markets for sun protection campaigns. In Proceedings for the ANZMAC Conference (pp. 144-149). Fremantle, Australia.

Kaffashi, S, Shamsudin, M.N., Sidique, S. F., Bazrbachi, A., Radam, A. Abdul Rahim, K., Adam, S. U. (2016) Choice experiment attributes selection: Problems and approaches in a modal shift study in Klang Valley, Malaysia. Asian Social Science, 12(1), 75-83. doi:10.5539/ass.v12n1p75

Kangari, R. (1995). Risk management perceptions and trends of US construction. Journal of Construction Engineering and Management, 121(4), 422-429. doi:10.1061/(asce)0733-9364(1995)121:4(422)

Karousakis, K., \& Birol, E. (2008). Investigating household preferences for kerbside recycling services in London: A choice experiment approach. Journal of Environmental Management, 88(4), 1099-1108. doi:10.1016/j.jenvman.2007.05.015

Kartam, A. N., \& Kartam, A. S. (2001). Risk and its management in the Kuwaiti construction industry: A contractors' perspective. International Journal of Project Management, 19(6), 325-335. doi:10.1016/ s0263-7863(00)00014-4

Kløjgaard, M. E., Bech, M., \& Søgaard, R. (2012). Designing a stated choice experiment : The value of a qualitative process. Journal of Choice Modeling 5(2), 1-18. doi:10.1016/s1755-5345(13)70050-2

Kometa, S. T., Olomolaiye, P. O., \& Harris, F. C. (1994). Attributes of UK construction clients influencing project consultants' performance. Construction Management and Economics, 12(5), 433-443. doi:10.1080/01446199400000053

Lancaster, K. J. (1966). A new approach to consumer theory. Journal of Political Economy, 74(2), $132-157$. doi: $10.1086 / 259131$

Leithead, A. (2017). The city that won't stopp growing; How can Lagos cope with its spiraling population. British Broadcasting Corporation (BBC). Retrieved August 21, from https:/www.bbc.co.uk/news/ resources/idt-sh/lagos

Louviere, J. J., Pihlens, D., \& Carson, R. (2011). Design of discrete choice experiments: A discussion of issues that matter in future applied research. Journal of Choice Modelling, 4(1), 1-8. doi:10.1016/s17555345(13)70016-2

Mangham, L. J., Hanson, K., \& McPake, B. (2009). How to do (or not to do) ... Designing a discrete choice experiment for application in a low-income country. Health Policy and Planning, 24(2), 151-158. doi:10.1093/heapol/czn047

Naz, A. C., \& Naz, M. T. (2005). Modeling choices for ecological solid waste management in suburban municipalities: User fees in Tuba, Philippines. Tanglin, Singapore: Economy and Environment Program for Southeast Asia.

Olukanni, D. O., \& Nwafor, C. O. (2019). Public-private sector involvement in providingeEfficient solid waste management services in Nigeria. Recycling, 4(2), 1-9. doi:10.3390/recycling4020019

Othman J. (2007) Economic valuation of household preference for solid waste management in Malaysia: a choice modeling approach. International Journal of Management Studies, 14(1), 189-212 
Pek, C. K., \& Jamal, O. (2011). A choice experiment analysis for solid waste disposal option: A case study in Malaysia. Journal of Environmental Management, 92(11), 2993-3001. doi:10.1016/j.jenvman.2011.07.013

Ramanathan, C., Narayanan, S., \& Idrus, A. B. (2012b). Construction delays causing risks on time and cost - a critical review. Australasian Journal of Construction Economics and Building, 12(1), 37-57. doi:10.5130/ ajceb.v12i1.2330

Smith, R. W. (1956). Product differenciation and market segmentation as alternative marketing strategies. Journal of Marketing, 21(1), 3-8. doi:10.1177/002224295602100102

Studenmund, A. H. (2001). Using econometrics: A practical guide ( $4^{\text {th }}$ Ed.). Boston, Massachusetts: AddisonWesley.

Wind, Y. (1978). Issues and advances in segmentation research. Journal of Marketing Research, 15(3), 317337. doi:10.1177/002224377801500302 
